\title{
An Approach to Modeling a Burning Cigarette*
}

\author{
by
}

Motohiko Muramatsu

Tobacco Institute of Japan (TIOJ) Testing Laboratory, 3-1-39 Wakamiya, Ishioka, Ibaraki 315-0017, Japan.

\section{SUMMARY}

The temperature and smoke components distributions inside a burning cigarette have been briefly reviewed. Then, focusing on our mathematical model to explain the natural smoldering mechanism of a cigarette and new mathematical models recently published by other authors, an approach to modeling a burning cigarette has been outlined.

It has been more than forty years since modeling the burning process of a cigarette was first attempted. Although the modeling work, which has been adopted as a means to research the burning mechanism of a cigarette, has seen a certain degree of progress in the last forty years, almost all mathematical models published are restricted to a burning cigarette under a free convection or a steady draw condition. No realistic model has been published yet to explain the processes occurring inside a burning cigarette under an intermittent puffing cycle. [Beitr. Tabakforsch. Int. 21 (2005) 286-293]

\section{ZUSAMMENFASSUNG}

Es wird ein kurzer Überblick über die Temperaturverhältnisse und die Verteilung von Rauchkomponenten in einer brennenden Zigarette gegeben. Danach wird auf der Basis unseres mathematischen Modells zur Erklärung des Glimmprozesses einer Zigarette und anhand neuer, von anderen Autoren publizierter mathematischer Modelle ein Ansatz zur Modellierung einer brennenden Zigarette präsentiert.

Vor mehr als vierzig Jahren wurde erstmals versucht, den Prozess einer brennenden Zigarette zu modellieren. Obwohl mit diesen Modellen, die dazu dienen, die Abbrennprozesse in einer Zigarette $\mathrm{zu}$ erforschen, in den letzten vierzig Jahren ein gewisser Fortschritt erzielt werden konnte, beschränken sich fast alle publizierten mathematischen Modelle auf eine brennende Zigarette unter den Bedingungen eines freien Konvektionsstroms oder eines konstanten Zuges. Kein realistisches Modell wurde bisher publiziert, um die Prozesse innerhalb einer brennenden Zigarette während eines intermittierenden Abrauchzyklus zu erklären. [Beitr. Tabakforsch. Int. 21 (2005) 286-293]

\section{RESUME}

Un bref aperçu sur la distribution de la température et des composants de la fumée à l'intérieur d'une cigarette incandescente est donné. Puis, en se basant sur un modèle mathématique pour expliquer le mécanisme de la combustion statique d'une cigarette, et des nouveaux modèles récemment publiés par d'autres auteurs, une approche permettant de modéliser une cigarette en combustion est présentée.

Depuis plus de quarante ans des modèles pour décrire le processus de combustion d'une cigarette ont été mis au point. Bien que certains progrès aient été réalisés pendant ces quarante dernières années avec ces modèles, appliqués comme moyen d'étudier le mécanisme de combustion d'une cigarette, presque tous les modèles mathématiques publiés sont limités aux processus de combustion à convection naturelle ou à tirage constant. Jusqu'à présent aucun modèle réaliste n'a été publié, permettant d'expliquer le processus à l'intérieur d'une cigarette incandescente lors de bouffées intermittentes. [Beitr. Tabakforsch. Int. 21 (2005) 286-293]

\footnotetext{
*Received: $24^{\text {th }}$ November 2005 - accepted: $19^{\text {th }}$ January 2005

This paper was presented, in part, at the 2004 CORESTA Congress, Kyoto, Japan
} 


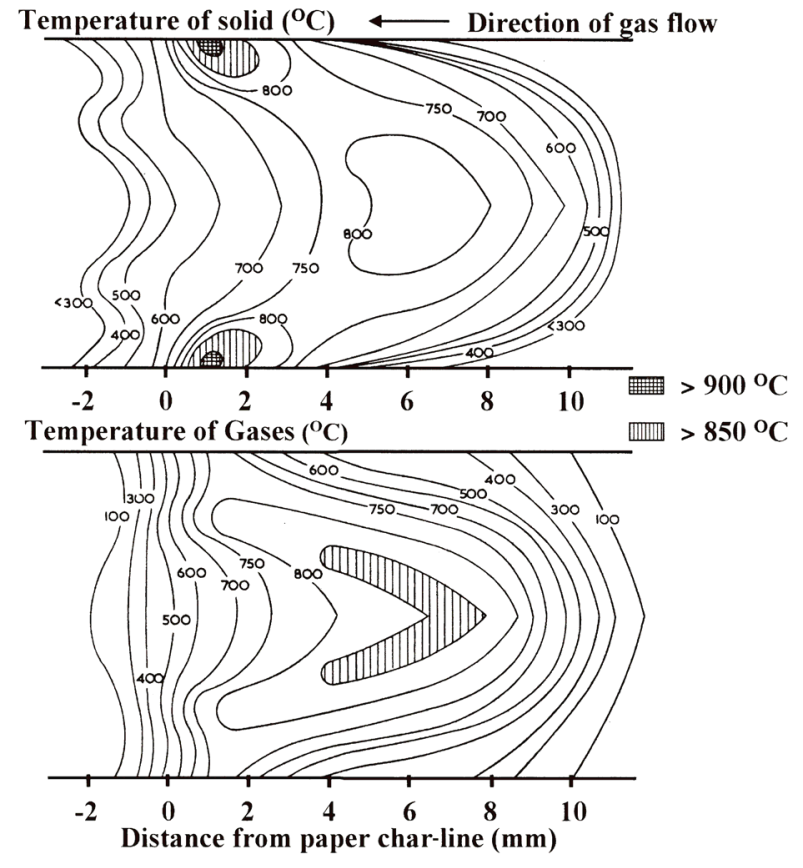

Figure 1. Temperature and concentration distributions inside a cigarette, 1.0 second from the start of a 2-second puff (13)

\section{INTRODUCTION}

It is considered to be important to develop a systematic understanding of the mechanisms of the combustion and smoke formation processes occurring inside a burning cigarette in order to design cigarettes. Research into the combustion and smoke formation processes of cigarettes progressed considerably from the 1970 s up to the mid 1980s, and our scientific knowledge regarding the compli- cated physical and chemical processes occurring inside a burning cigarette increased greatly during this period. The progress made owes much to the work conducted by BAKER at British American Tobacco in Southampton. Progress made in terms of research in these fields, including modeling studies of the burning process, after the $1970 \mathrm{~s}$ has been reviewed frequently (e.g., 1-6).

In this paper, the temperature and smoke components distributions in a burning cigarette will be briefly reviewed. Then, focusing on our mathematical model to explain the natural smoldering mechanism of a cigarette and new mathematical models recently published by other authors, an approach to modeling a burning cigarette will be outlined.

\section{TEMPERATURE AND SMOKE COMPONENTS DISTRIBUTIONS}

Since both the combustion and smoke formation processes are highly dependent on the temperature distribution within a burning cigarette, the first step in the study began in many cases with the measurement of the burning temperature. Consequently, many papers associated with temperature measurement have been published (e.g., 7-13). BAKER $(12,13)$ measured the temperature distributions of both the gas and solid phases inside a burning cigarette under a steady draw condition and during an intermittent puff cycle as shown in Figure 1. Solid phase and gas phase temperatures were measured with an infrared transmitting fiber optic probe and a small thermocouple, respectively.

BAKER also measured the distributions of low molecular weight gases within a burning cigarette during an intermittent puff cycle (14) following the measurement of those exposed to steady draws $(15,16)$, as shown in Figure 2. A sample probe coupled directly to a mass spectrometer or
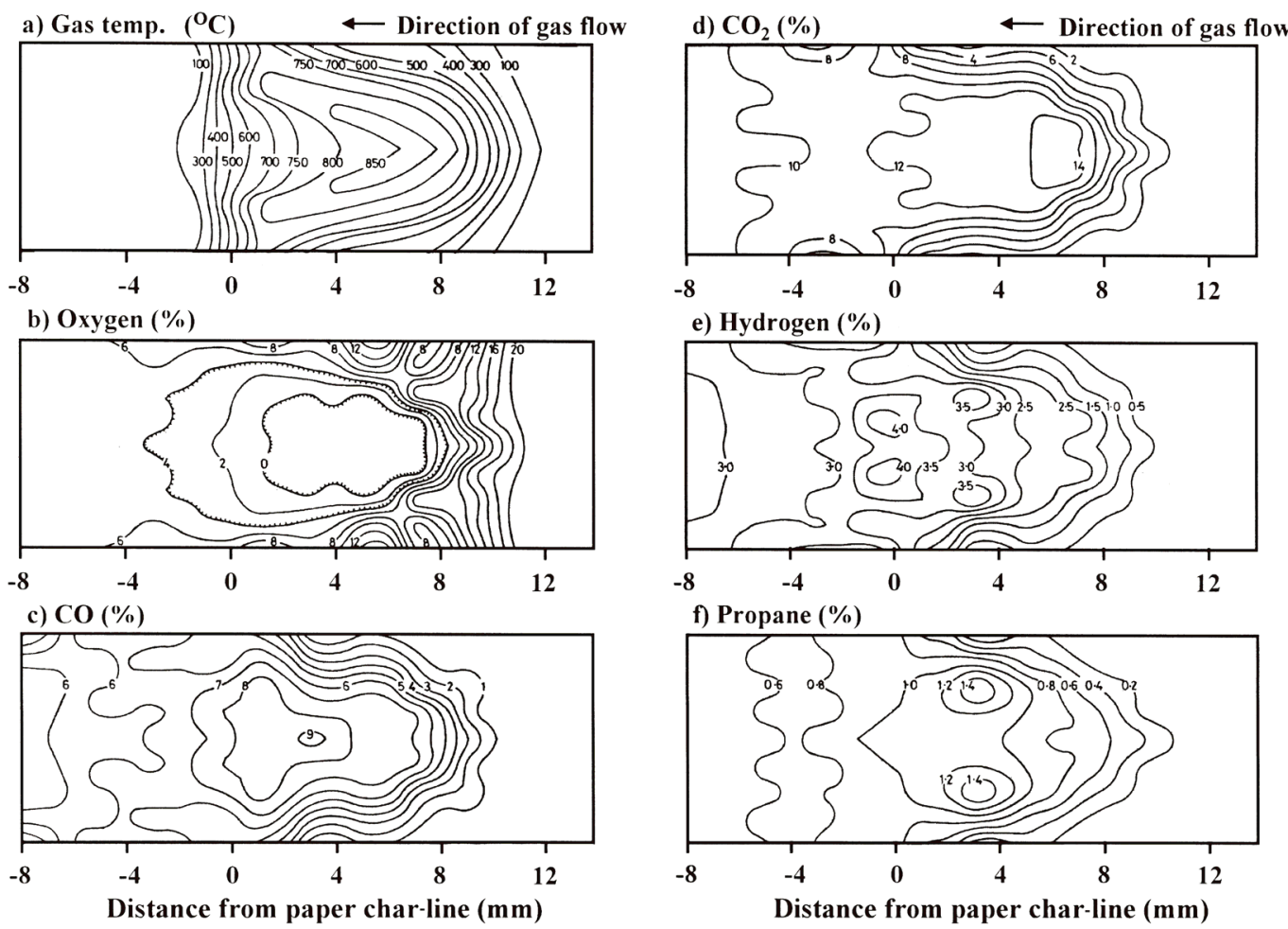

Figure 2. Gas temperature and concentration distributions inside a cigarette, 1.0 second from the start of a 2-second puff (14) 
Table 1. Mathematical models of a burning cigarette proposed by the late $1980 \mathrm{~s}$

\begin{tabular}{|c|c|c|c|c|}
\hline Year and reference & Author(s) & Geometry & Smoking condition & Note \\
\hline $1963(19)$ & Egerton et al. & $1-D$ & Steady draw & $\begin{array}{l}\text { First attempt at modeling burning cigarette. Involving } \\
\text { lack of thermal equilibrium between solid and gas } \\
\text { phases }\end{array}$ \\
\hline $1966(20)$ & Gugan & 2-D & Natural smolder & $\begin{array}{l}\text { Isothermal oxygen diffusion model to simulate the } \\
\text { consumption of a combustion coal surface }\end{array}$ \\
\hline $1977(21)$ & $\begin{array}{l}\text { Simpson and } \\
\text { Wymack }\end{array}$ & $1-D$ & Natural smolder & $\begin{array}{l}\text { Involving char oxidation and pyrolysis of four } \\
\text { tobacco components }\end{array}$ \\
\hline $1977(22)$ & Baker & $1-D$ & Steady draw & $\begin{array}{l}\text { Simple mass and heat conservation model involving } \\
\text { lack of thermal equilibrium between solid and gas } \\
\text { phases to estimate the rate of heat generation by } \\
\text { chemical reaction }\end{array}$ \\
\hline $1978(23)$ & Summerfield et al. & $1-D$ & Steady draw & $\begin{array}{l}\text { Composed of a series of differential equations } \\
\text { based on conservation laws of mass, heat and } \\
\text { momentum, involving lack of thermal equilibrium } \\
\text { between solid and gas phases }\end{array}$ \\
\hline $1979(24)$ & Muramatsu et al. & $1-D$ & Natural smolder & Referred to in the text \\
\hline $1981(25)$ & Muramatsu & $2-D$ & Natural smolder & Referred to in the text \\
\hline $1985(26)$ & $\begin{array}{l}\text { Lawson and } \\
\text { Norbury }\end{array}$ & $1-D$ & $\begin{array}{l}\text { Steady draw but } \\
\text { drawing rate was } \\
\text { changed linearly in } \\
\text { a step function }\end{array}$ & $\begin{array}{l}\text { Although not for cigarette, the model is very relevant } \\
\text { to cigarette combustion }(5,6) \text {. Considered lack of } \\
\text { thermal equilibrium between solid and gas phases } \\
\text { and time dependent features. }\end{array}$ \\
\hline $1989(27)$ & Norbury and Stuart & $3-D$ & Steady draw & $\begin{array}{l}\text { Although not for cigarette, the model is very relevant } \\
\text { to cigarette combustion }(5,6) \text {. Considered lack of } \\
\text { thermal equilibrium between solid and gas phases } \\
\text { and time dependent features. No attempt was made } \\
\text { to solve the model equations delivered. }\end{array}$ \\
\hline
\end{tabular}

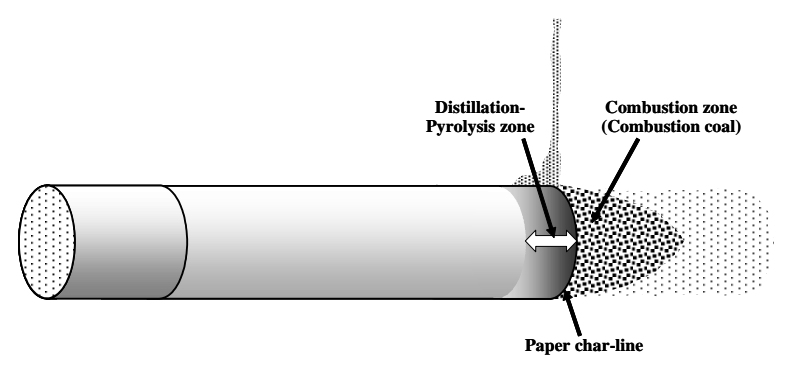

Figure 3. Distillation-pyrolysis and combustion zones in a naturally smoldering cigarette

carbon monoxide meter was used for the measurement. Then, such probe studies were extended to the sidestream plume (17) and to major semi-volatile products (18). Through a series of these studies, the regions in which major gases, semi-volatile smoke constituents and the sidestream smoke plume were formed inside or above the burning cigarette, and how these regions varied during the smoking cycle, were determined. Since these results have been reviewed comprehensively $(1-3,6)$, a more detailed explanation about those will be omitted.

\section{CIGARETTE BURNING MODELS PROPOSED BY THE LATE 1980s}

Mathematical models (19-27) of a burning cigarette proposed by the late 1980s are summarized in Table 1 . Much of the significant progress in the mathematical modeling of the burning cigarette was made in the mid 1970s to early 1980s. These models incorporated some principal parameters controlling physical and chemical processes such as pyrolysis and combustion accompanied by the generation of smoke and heat. Since (i) these models have been reviewed comprehensively $(1,3-6)$, (ii) the main part of our mathematical model (25) to explain the natural smoldering mechanism of a cigarette was written in Japanese, and fortunately (iii) our model does not seem to be outdated yet though it was published more than 20 years ago, our mathematical model $(24,25)$ will be outlined.

The extensive studies $(15,16,28-30)$ conducted by the late 1970s demonstrated that the interior of the burning zone of a cigarette is oxygen deficient and can be effectively divided into two regions: the endothermic distillationpyrolysis zone and the exothermic combustion zone, as illustrated in Figure 3. These results prompted us to draw up a simplified scheme of the major processes inside a burning cigarette (25), as shown in Figure 4. When the tobacco is heated, moisture and volatile components are first vaporized or distilled. Pyrolysis of the tobacco components then occurs, and various volatiles are generated, leaving a tobacco char. This is termed the distillationpyrolysis process. In a further process, the char is oxidized by oxygen and leaves ash. The oxidation of the char generates heat and gaseous products such as carbon oxides. This is called the combustion process. Some of the heat generated in this process is transferred back to the distillation-pyrolysis zone, which forms a self-sustaining smoldering cycle of the cigarette. This is called the heat transfer process. Thus, the major burning processes of the cigarette are regarded as consisting of these three basic processes. 


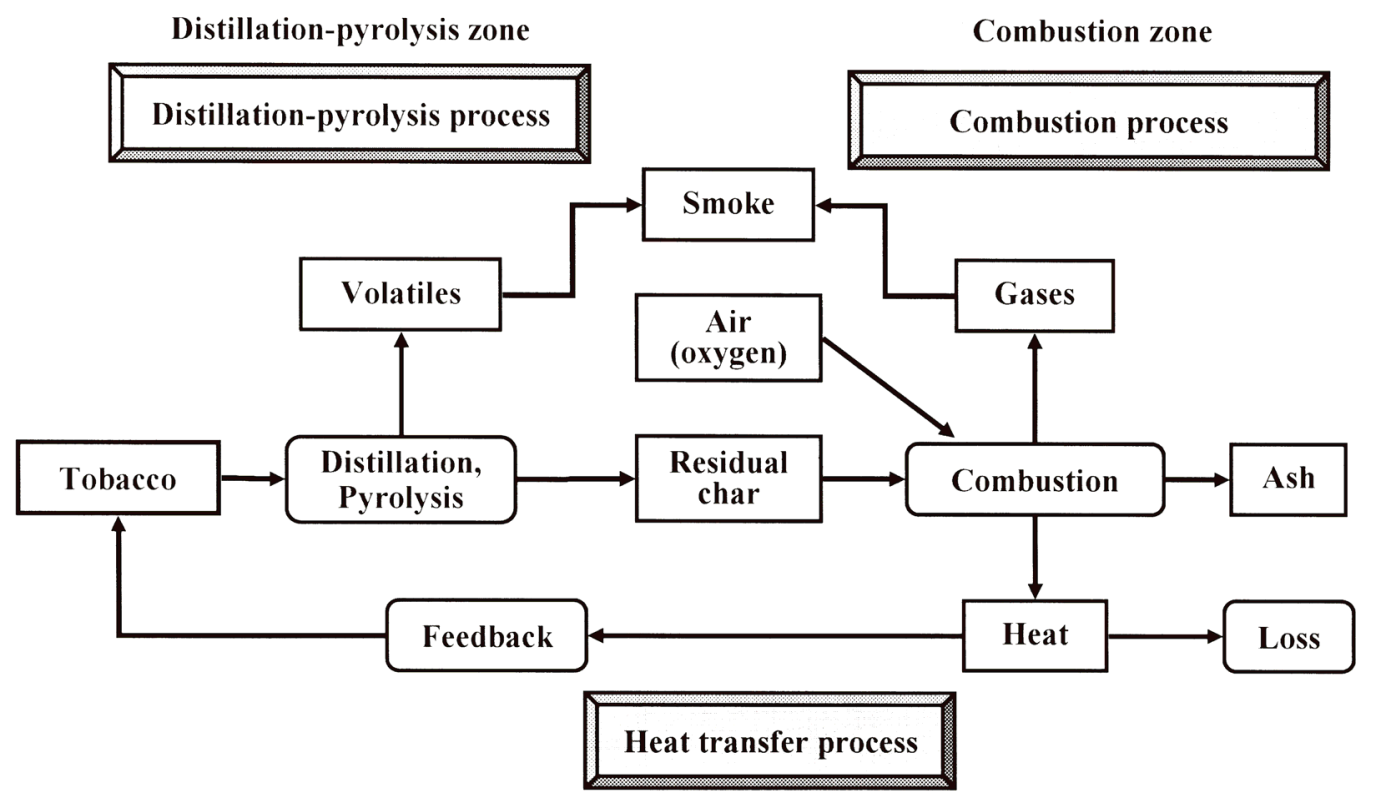

Figure 4. Simplified scheme of the major processes occurring in a burning cigarette (25)

The supply of oxygen to the combustion zone is governed by free convection between puffs and by forced convection during puffs. The heat transfer back to the distillationpyrolysis zone depends on the effective thermal conductivity of the tobacco column between puffs and forced heat convection during puffs. During a puff, therefore, a large quantity of oxygen is supplied to the combustion zone. This results in promotion of the oxidation of the char and the generation of heat energy. Since the heat generated is effectively transferred to the unburnt tobacco by forced heat convection as a hot wind, the distillation-pyrolysis process is also promoted during a puff. Consequently, the burning rate and peak temperature rise remarkably during a puff, and hence the amount of tobacco consumed and smoke formed significantly increase at this time. The differences in the peak temperature, the rate of the oxygen supply, and the heat transfer should affect the smoke composition of the mainstream smoke produced during a puff and the sidestream smoke produced mainly between puffs.

According to this scheme, we developed a one-dimensional mathematical model for the distillation-pyrolysis zone (24) and a two-dimensional mathematical model for the combustion zone (25) that explain the mechanism of the natural smoldering of a cigarette. These models were based on the experimental results and the postulated smoldering mechanism of a cigarette as follows:

1) Endothermic evaporation of water from tobacco shreds following a mass-transfer and rate-determined process (distillation-pyrolysis zone)

2) Four pyrolysis reactions of tobacco shreds expressed by n-th order Arrhenius kinetics, which yield volatiles leaving a char (distillation-pyrolysis zone)

3) Two oxidation reactions of the char expressed by n-th order Arrhenius kinetics, which yield gases, leaving ash and generating combustion heat proportional to the oxygen consumption (combustion zone)

4) Weight loss due to evaporation, pyrolysis and oxidation (distillation-pyrolysis and combustion zones)
5) Two-dimensional configurations of the combustion zone, i.e., radial variations of temperature, density and oxygen concentration as well as longitudinal variations (combustion zone)

6) Oxygen supply to the outer surface of the combustion zone by free convection and diffusion of the oxygen from this point to within the combustion zone (combustion zone)

7) Internal heat transfer characterized by effective thermal conductivity consisting of thermal conduction and radiation (distillation-pyrolysis and combustion zones)

8) Heat loss attributable to free convection and radiation from the outer surface of the cigarette (distillationpyrolysis and combustion zones)

9) Thermal equilibrium between the gas phase and the solid phase (distillation-pyrolysis and combustion zones), and

10) Boundary of the distillation-pyrolysis zone and combustion zone corresponding to the paper char-line, i.e., the bottom of the combustion zone that was defined by the completion of the pyrolysis of cellulose constituting tobacco (distillation-pyrolysis and combustion zones).

The two-dimensional model for the combustion zone was the first attempt to accommodate the radial variations for the combustion coal of a burning cigarette.

The heat and mass transfer phenomena in both the distillation-pyrolysis and combustion zones of a naturally smoldering cigarette were expressed through a set of simultaneous ordinary or partial differential equations, respectively. These two models were merged at the paper char-line under the following condition: that the heat flow required in the distillation- pyrolysis zone and that supplied from the combustion zone to the distillation-pyrolysis zone were balanced.

The set of simultaneous differential equations was solved numerically assuming given reasonable initial and boundary conditions and physical parameters. Most of the input parameters were measured experimentally. The predicted smoldering rate and peak temperature were approximated 
Table 2. Comparison of predicted results and experiment results (25)

\begin{tabular}{l|cc|c|c}
\hline \multirow{2}{*}{ Cigarette } & $\begin{array}{c}\text { Linear smoldering rate } \\
(\mathrm{cm} / \mathrm{min})\end{array}$ & \multicolumn{2}{c}{$\begin{array}{c}\text { Peak temperature } \\
\left({ }^{\circ} \mathrm{C}\right)\end{array}$} \\
\cline { 2 - 5 } & Predicted & Experimental & Predicted & Experimental \\
\hline A & 0.329 & 0.324 & 823 & 812 \\
B & 0.312 & 0.248 & 838 & 805 \\
C & 0.523 & 0.461 & 856 & 812 \\
D & 0.375 & 0.308 & 843 & 798 \\
E & 0.437 & 0.455 & 829 & 807 \\
F & 0.426 & 0.341 & 848 & 802 \\
\hline
\end{tabular}

to the experimental results (25), as shown in Table 2 . Comparison of predictions with experimental results for temperature distribution and shape of the combustion coal are illustrated in Figure 5. Close agreement between predictions and experimental results was obtained.

The effect of the individual parameters such as the radius and packing density of cigarettes on the smoldering features could be predicted quantitatively based on the proposed model. Agreement between predictions and experiment results was very good for most parameters. This model, however, was too sensitive for the parameters relating to oxygen transfer, and it did not include parameters for the properties of cigarette paper affecting the smoldering features.

\section{CIGARETTE BURNING MODELS PROPOSED RECENTLY}

Research into the combustion and smoke formation processes within cigarettes decreased from the mid 1980s onwards. Reports related to this area of research, however, seem to be increasing recently. These reports include
Table 3. Mathematical models of a burning cigarette published recently

\begin{tabular}{llll}
\hline $\begin{array}{l}\text { Year and } \\
\text { Reference }\end{array}$ & Author(s) & Geometry & Smoking condition \\
\hline $2001(36)$ & Miura et al. & 1-D & Natural smolder \\
$2001(37)$ & Yi et al. & 2-D & Natural smolder \\
$2002(38)$ & Chen & 1-D & Natural smolder \\
$2003(39)$ & Rostami et al. & 2-D & Natural smolder \\
$2004(40)$ & Rostami et al. & 2-D & $\begin{array}{l}\text { Natural smolder, } \\
\text { steady draw }\end{array}$ \\
& & & \\
\hline
\end{tabular}

research into the propensity of a cigarette to ignite upholstery or the ignition mechanism of cellulosic fabrics by a naturally smoldering cigarette in relation to the "Fire Safe Cigarette" (e.g., 31-35). A few mathematical models of the burning process have also been published recently by MIURA et al. (36) of Japan Tobacco, Yi et al. (37) of Hanyang University and Philip Morris USA, CHEN (38) of Philip Morris USA, and Rostami et al. $(39,40)$ of Philip Morris USA and Carnegie Mellon University as summarized in Table 3.

MIURA (41) recently presented new findings about the role that the cigarette paper plays in a burning cigarette. It has been recognized that the rate of oxygen supply to the burning zone of cigarette by the diffusion through the cigarette paper depends on oxygen diffusivity through the virgin cigarette paper and directly influences the smoldering rate $(2,42)$. MIURA, however, showed that oxygen diffusion coefficient through the virgin cigarette paper is not related to the oxygen supply in a smoldering cigarette, and concluded that oxygen diffusivity through the cigarette paper was not the only factor to control the smoldering rate of the cigarette. Then, MIURA et al. (36) focused on the burning near the paper char-line of a naturally smoldering

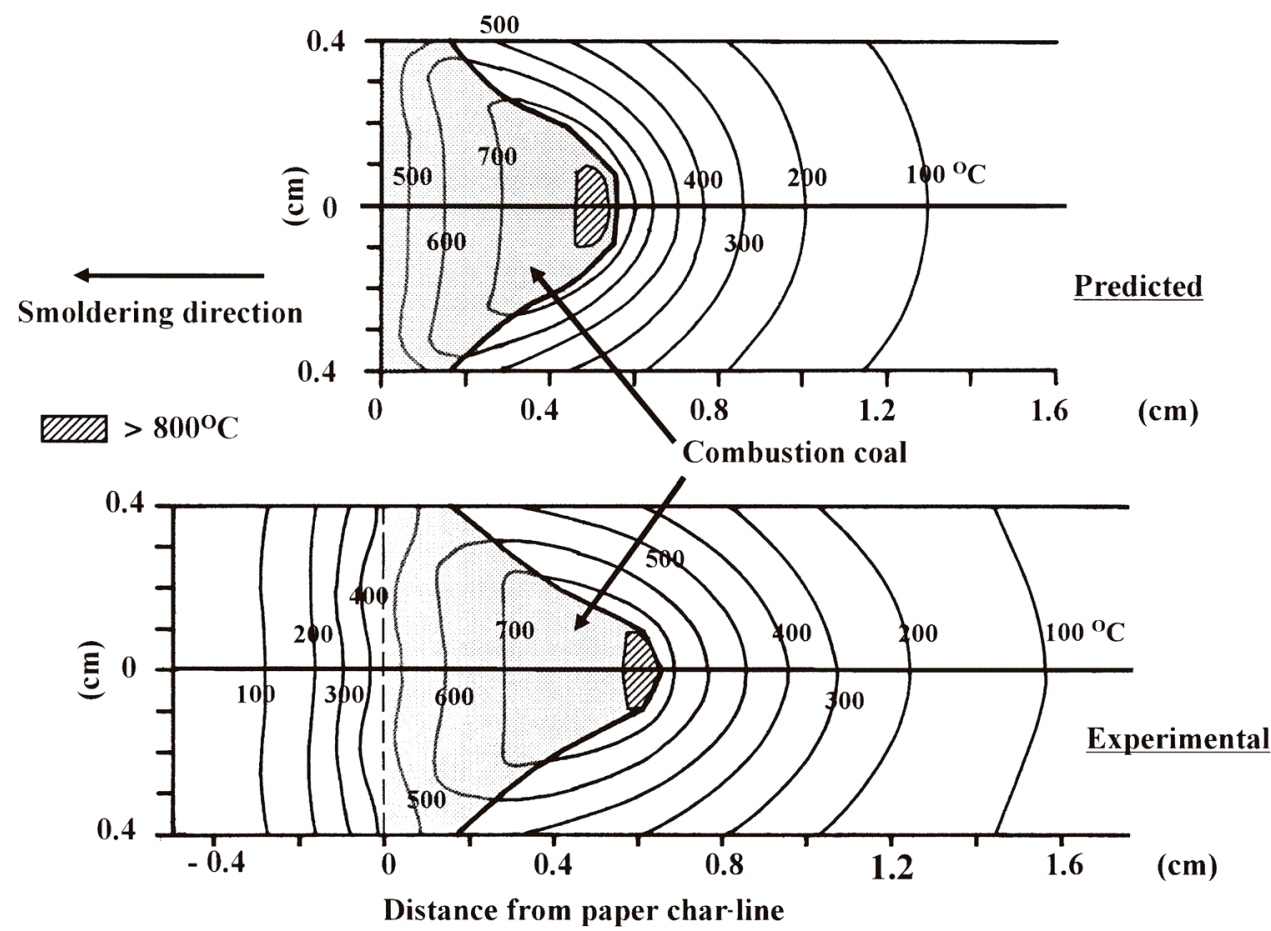

Figure 5. Comparison of predictions with experimental results for temperature distribution and shape of combustion coal of a naturally smoldering cigarette (25) 


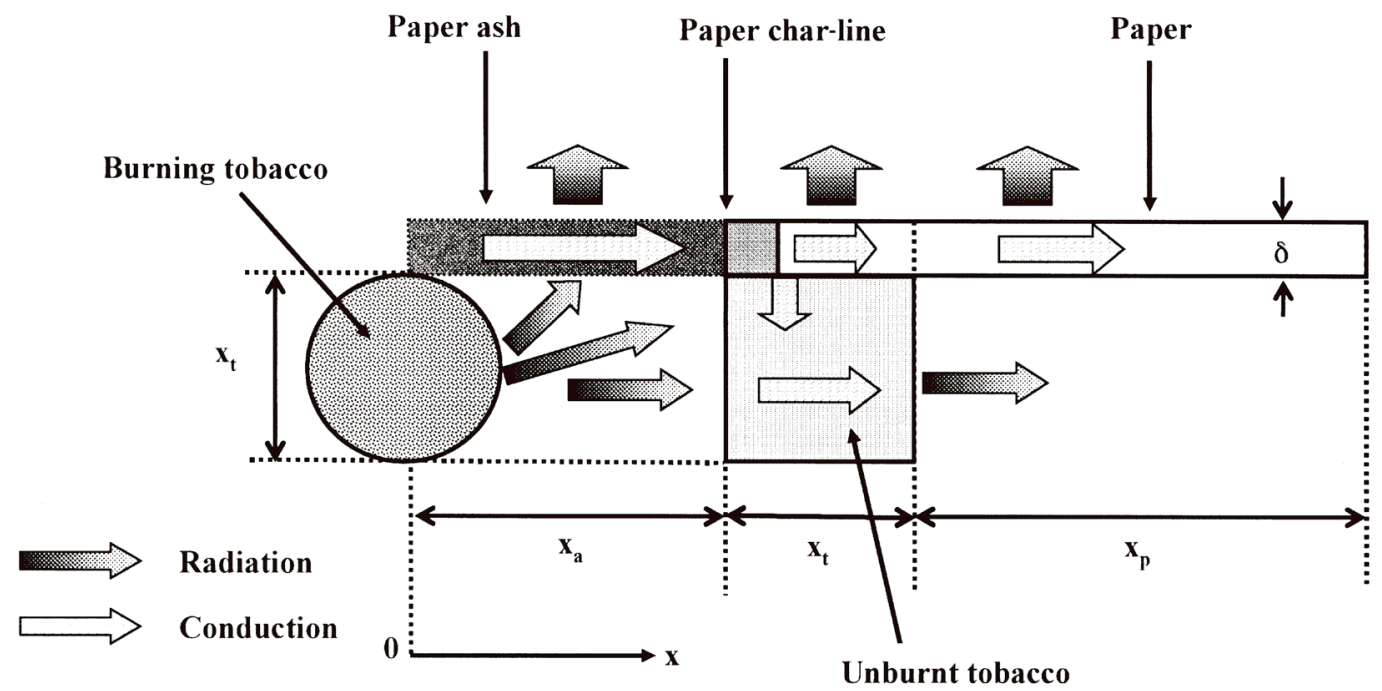

Figure 6. Schematic diagram of a mathematical model at the cigarette periphery near the char-line (36)

cigarette. The authors characterized the propagation of natural smoldering by an intermittent flash burn of the cigarette paper observed at the cigarette periphery and concluded that the smoldering rate is determined predominantly by the time required for re-igniting the charred cigarette paper and that cigarettes with a higher smoldering rate exhibit a higher increase in temperature of the charred cigarette paper. Assuming that burning at the periphery controls the propagation of the natural smoldering, and that the interaction between tobacco shred and cigarette paper plays an important role in the smoldering, the authors proposed a propagation model for the periphery of a naturally smoldering cigarette, as illustrated in Figure 6. The mathematical model consists of heat transfer equations for the cigarette paper and the tobacco shred. The predicted temperature variation of the paper char-line agreed reasonably well with the measure one. The model demonstrated that the thermal properties of the cigarette periphery are the dominant rate-limiting factors of natural smoldering. However, the smoldering rate was measured for a cigarette positioned vertically but not horizontally, and the proposed model did not directly predict the smoldering rate.

A naturally smoldering model for a cylindrical carbonaceous porous medium including cigarette was presented by YI et al. (37) to elucidate the mechanism of smoldering. The smoldering process of the cylindrical medium was segregated into two reaction zones - a pyrolysis zone and a combustion zone. Two independent models were developed: a steady-state two-dimensional model for the pyrolysis zone resulting in char formation, and a steady-state twodimensional model for the combustion zone, i.e., char oxidation. The interface temperature between the two zones is defined as the temperature at which the pyrolysis is complete or the residual char ignites, which can be determined experimentally. In their models, our one-dimensional model for the pyrolysis zone and two-dimensional model for the combustion zone $(24,25)$ mentioned above are broadly adopted with some modifications as well as the variable physical properties. The pyrolysis model proposed is improved by extending our model (24) to two-dimensions. Predicted temperature and density profiles at the centerline and outer surface in a pyrolysis zone agreed well with experimental profiles obtained by MURAMATSU et al. (24). Predicted two-dimensional temperature contours of the combustion zone were extremely similar to those shown in the upper part of Figure 5.

Meanwhile, CHEN (38) proposed a one-dimensional mathematical model of a naturally smoldering cigarette where the cigarette is divided into two zones, the pyrolysis zone and the combustion zone at $450{ }^{\circ} \mathrm{C}$. The pyrolysis of tobacco and evaporation of water in the pyrolysis zone and the char combustion processes generating a large amount heat and producing a hot gas in the combustion zone are included in the model. Heat transfer inside the cigarette is characterized by effective thermal conductivity in each zone. Heat loss due to convection and radiation from the outer surface to the environment is considered. These processes were expressed by a series of differential equations concerning heat and mass transfers, which were solved by using an integral method. In this manner, the concept of his model also seems to be similar to that of our model $(24,25)$ in several ways. However, in his model the concentration of oxygen was not considered in the char combustion, and temperature profiles in the pyrolysis zone and combustion zone were given a certain function, respectively. The predictions of the temperature and density profiles in a naturally smoldering cigarette correlated well with the experimental results, as shown in Figure 7.

ROSTAMI et al. (39) developed a transient two-dimensional model of a naturally smoldering cigarette consisting of a set of partial differential equations concerning flow, heat and mass transfer. The model includes water evaporation, four pyrolysis reactions of tobacco and two oxidation reactions of char, similar to those in our model $(24,25)$, in addition to distinct solid and gas temperatures, tobacco rod permeability and paper permeability. The computation captures the development of a steady-state combustion regime in which the smoldering front moves at a constant rate. Comparing the predictions with the experimental data on the smoldering rate, the peak solid and gas temperatures validated the model. The smoldering rate and temperature, coal shape, solid and gas temperature distributions, product yields, and tobacco density variation could be predicted from the computation. However, accurate comparison of predicted 

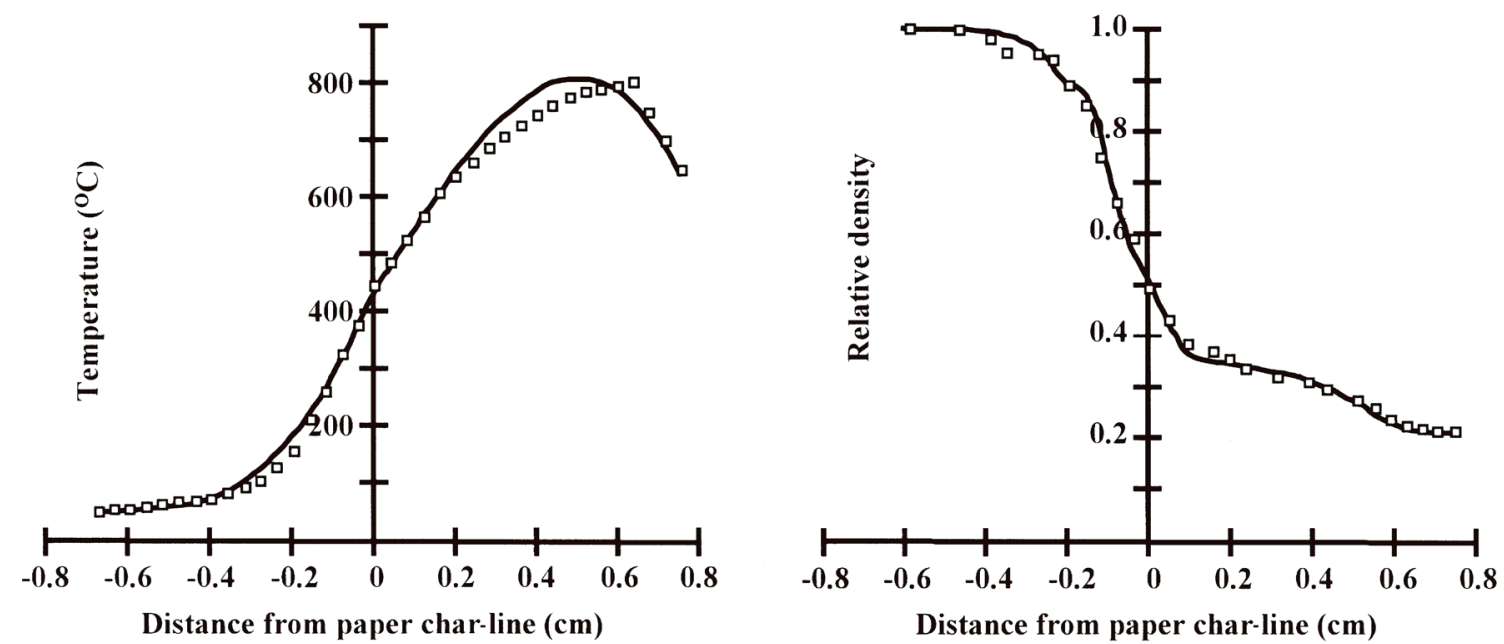

Figure 7. Comparison of predictions with experimental results for temperature and density profiles of a naturally smoldering cigarette (38)

and experimental results was not shown. The results are shown to be very sensitive to the oxygen diffusivity through the cigarette paper. This model has been extended to the burning process of a porous biomass fuel rod including a cigarette under a steady draw condition (40).

\section{CONCLUSION}

It has been more than forty years since EGERTON et al. (19) first tried to model the burning process of a cigarette. Although the modeling work, which has been adopted as a means to research the burning mechanism of a cigarette, has seen a certain degree of progress in the last forty years, almost all mathematical models published are restricted to a burning cigarette under a free convection or a steady draw condition. No realistic model has been published yet which explains the processes occurring inside a burning cigarette under an intermittent puffing condition. Such a model would be useful for simulating the actual smoking of cigarettes; however, the development of the model will face unavoidable time-dependent features associated with puffing that will need to be dealt with. I expect that models involving time dependent features and lack of thermal equilibrium between solid and gas phases, such as those proposed by LAWSON and NORBURY (26), and ROSTAMI $e t$ al. (39), respectively, will serve as steps toward extending the model development to an intermittent puffing condition.

\section{ACKNOWLEDGMENT}

The author would like to thank Dr. Richard R. Baker, Senior Principal Scientist, R \& D Centre, British American Tobacco, for his valuable advice in the preparation of this manuscript.

\section{REFERENCES}

1. Baker, R.R.: Product formation mechanisms inside a burning cigarette; Prog. Energy Combust. Sci. 7 (1981) 135-153.

2. Baker, R.R.: The effect of ventilation on cigarette combustion mechanisms; Rec. Adv. Tob. Sci. 10 (1984) 88-150

3. Baker, R.R.: Some burning problems in tobacco science; Proceedings of the International Conference on the Physical and Chemical Processes Occurring in a Burning Cigarette, Winston-Salem, N.C., 1987, pp. $1-61$.

4. Ohlemiller, T.J.: Aspects of smoldering combustion; Proceedings of the International Conference on the Physical and Chemical Processes Occurring in a Burning Cigarette, Winston-Salem, N.C., 1987, pp. 346-354.

5. Baker, R.R. and D.P. Robinson: Review of mathematical models of smoke formation; Proceedings of CORESTA Symposium, Technical Group Papers, Kallithea, 1990, pp. 20-27.

6. Baker, R.R. and D.P. Robinson: Tobacco combustion - The last ten years; Rec. Adv. Tob. Sci. 16 (1990) 3-71.

7. Touey, G.P. and Mumpower II, R.C.: Measurement of the combustion zone temperature of cigarettes; Tob. Sci. 1 (1957) 33-37.

8. Kobashi, Y., S. Sakaguchi, and M. Izawa: Influence of smoking procedures on combustion temperature of cigarettes and the nicotine content of cigarette smoke; Bull. Agric. Chem. Soc. Japan 23 (1959) 528-532.

9. Muramatsu, M., Y. Obi, T. Fukuzumi, and T. Keii; Influence of continuous puff velocity on combustion rate, temperature and temperature distribution in cigarettes; J. Agric. Chem. Soc. Japan 46 (1972) 569-575. 
10. Laszlo, T.S. and F.M. Watson III: A scanning infrared technique for cigarette coal peak temperature measurements; Beitr. Tabakforsch. 7 (1974) 269-275.

11. Lendvay, A.T. and T.S. Laszlo: Cigarette peak coal temperature measurements; Beitr. Tabakforsch. 7 (1974) 276-281.

12. Baker, R.R.: Temperature distribution inside a burning cigarette; Nature 247 (1974) 405-406.

13. Baker, R.R.: Temperature variation within a cigarette combustion coal during the smoking cycle; High Temp. Sci. 7 (1975) 236-247.

14. Baker, R.R.: Variation of the gas formation regions within a cigarette combustion coal during the smoking cycle; Beitr. Tabakforsch. Int. 11 (1981) 1-17.

15. Baker, R.R. and K.D. Kilburn; The distribution of gases within the combustion coal of a cigarette; Beitr. Tabakforsch. 7 (1973) 79-87.

16. Baker, R.R.: Environmental conditions inside a burning cigarette; in: Analytical Calorimetry, Vol. 4, edited by R.S. Poster and J.F. Johnson, Plenum Publishing, New York, N.Y., 1977, pp. 21-35.

17. Baker, R.R.: Variation of sidestream gas formation during smoking cycle; Beitr. Tabakforsch. 11 (1982) 181-193.

18. Baker, R.R.: The release of nicotine and semi-volatile components inside a burning cigarette; Proceedings of CORESTA Symposium, Taormina, Sicily, 1986, pp. 522-532.

19. Egerton, Sir A., K. Gugan, K., and F.J. Weinberg: The mechanism of smoldering in cigarettes; Combust. Flame 7 (1963) 63-78.

20. Gugan, K.: Natural smolder in cigarettes; Combust. Flame 10 (1966) 161-164.

21. Simpson, D.L. and Waymack, B.E.: A one-dimensional model of the smoldering cigarette; Paper presented at the 31st Tob. Chem. Res. Conf., Greensboro, NC, USA, 1977, Program Booklet and Abstracts, Vol. 31, Paper No. 19, 1997, p. 10.

22. Baker, R.R.: Combustion and thermal decomposition regions inside a burning cigarette; Combust. Flame 30 (1977) 21-31.

23. Summerfield, M., T.J. Ohlemiller, and H.W. Sandusky: A thermophysical mathematical model of steady-draw smoking and prediction of overall cigarette behavior; Combust. Flame 33 (1978) 263-279.

24. Muramatsu, M., S. Umemura, and T. Okada: A mathematical model of evaporation-pyrolysis processes inside a naturally smoldering cigarette; Combust. Flame 36 (1979) 245-262.

25. Muramatsu, M.: Studies on the transport phenomena in naturally smoldering cigarettes; Sci. Pap. Centr. Res. Inst. Jap. Tob. and Salt Pub. Corp. 123 (1981) 9-78.

26. Lawson, D.A. and J. Norbury: Combustion in porous medium; in: Numerical Heat Methods in Thermal Problems, Volume 3, edited by R.W. Lewis, John Wiley \& Sons, 1985, pp. 173-193.

27. Norbury, J. and A.M. Stuart: A model for porousmedium combustion; Quart. J. Mech. Appl. Math. 42, Pt. 1 (1989) 159-178.

28. Hobbs, M.E.: A study of some possible chemical equilibria in the gas phase of cigarette smoke; Tob. Sci. 1 (1957) 74-77.
29. Lanzillotti, H.V. and A.R. Wayte: One-dimensional gas concentration profiles within a burning cigarette during a puff; Beitr. Tabakforsch. 8 (1975) 219-224.

30. Newsome, J.R. and C.H. Keith: Variation of the gas phase composition within a burning cigarette; Tob. Sci. 9 (1965) 65-69.

31. Mitler, H.E. and G.N. Walton: Modeling the ignition of soft furnishings by a cigarette; NIST special publication 852, Report 3, 1993.

32. Dyakonov, A., D. Grider, and A.M. Ihrig: The mechanisms of anisotropic smolder of a peculiarly treated cellulosic fabric; Paper Presented at $51^{\text {st }}$ Tob. Chem. Res. Conf., Winston-Salem, NC, USA, 1997, Program Booklet and Abstracts, Vol. 51, Paper No. 41, 1997, p. 49.

33. Wu, E.C. and D. Grinder: A new approach to the fabric ignition study by a simulated smoldering cigarette; Paper Presented at 51 $1^{\text {st }}$ Tob. Chem. Res. Conf., Winston-Salem, NC, USA, 1997, Program Booklet and Abstracts, Vol. 51, Paper No. 42, 1997, p. 49.

34. Chen, P., D.S. Kellogg, B.E. Waymack, and D.D. McRae: A model of fabric smoldering ignition by cartridge heaters; Proceedings of the CORESTA Smoke and Technology Groups Meeting, Hamburg, Germany, 1997, pp. 362-370.

35. Watkins, M.L. and J.S. Jones: Characterization of the heat transfer for cigarette ignition propensity substrates using transient thermal analysis; Paper presented at CORESTA Smoke and Technology Groups Meeting, Xian, China, 2001, Abst. No. ST28.

36. Miura, K., S. Kitao, Y. Egashira, N. Nishiyama, and K. Ueyama: Propagation of cigarette static burn; Beitr. Tabakforsch. Int. 19 (2001) 277-287.

37. Yi, S.-C., E.-S. Song, and M. Hajaligol: Mathematical model of smoldering combustion in a carbonaceous porous medium, Part 1. Development of pyrolysis and combustion models for a cylindrical geometry; J. Fire Sci. 19 (2001) 429-448.

38. Chen, P.: A mathematical model of cigarette smoldering process; Beitr. Tabakforsch. Int. 20 (2002) 265-271.

39. Rostami, A., J. Murthy, and M. Hajaligol: Modeling of a smoldering cigarette; J. Anal. Appl. Pyrolysis 66 (2003) 281-301.

40. Rostami, A., J. Murthy, and M. Hajaligol: Modeling of smoldering process in a porous biomass fuel rod; Fuel 83 (2004) 1527-1536.

41. Miura, K.: Oxygen diffusion through cigarette paper; Beitr. Tabakforsch. Int. 19 (2001) 205-208.

42. Owens, W.F., Jr.: Effect of cigarette paper on smoke yield and composition; Rec. Adv. Tob. Sci. 4 (1978) 3-24.

\section{Corresponding author}

Motohiko Muramatsu

Tobacco Institute of Japan (TIOJ) Testing Laboratory

3-1-39 Wakamiya, Ishioka

Ibaraki 315-0017

Japan

E-mail: tiojlab.mm@nifty.com 